In 2003 the Cultural Center Bank of Brazil (São Paulo, created in 2001) decided to make a research to know about the reception of the printed material they produced for the program "Dialogue and reflection" with art teachers. The CCBB-SP wanted to know what the teachers were doing in their classroom with the material that comprised a printed pamphlet (16 to 18 pages) discussing art issues related with the major exhibitions (4 by year) plus images in transparences to facilitate their projection for the students.

Key-words: interdisciplinary, intercultural, arts integration. 


\title{
Arte na educação: interterritorialidade, interdisciplinaridade e outros inter
}

\author{
Ana Mae \\ BARBOSA
}

Colaboração: Mercedes Frígola Pardo

Os artistas e agentes culturais hoje se formam principalmente nas Universidades. A maioria delas ainda não percebeu que os currículos engessados pelas especialidades já não respondem às interconexões, interpenetrações e sincretismos gerados por valores culturais mais democráticos e pelas novas tecnologias. Do mesmo modo poucas Universidades se atualizaram no sentido da ampliação do seu repertório baseado no código europeu e norte americano branco que sempre as dominou para incluir outros códigos culturais na educação de artistas e atores culturais. Portanto queremos chamar a atenção para a interculturalidade, a interdisciplinaridade e a integração das Artes e dos meios como modos de produção e significação desafiadores de limites, fronteiras e territórios que reclamam uma visão rearticuladora do mundo e de nós mesmos. Podemos usar o trabalho de Mercedes Frigola, professora da Rede Municipal de São Paulo, em 2004, como excelente exemplo de interdisciplinaridade e de um ensino de Arte de qualidade. Palavras-chave: interculturalidade, interdisciplinaridade, integração das artes. 
De junho a agosto de 2005, coordenei no SESC uma série de cursos/encontros que compuseram a trilogia "Interritorialidade: fronteiras intermídias, contextos e educação". Tive como coordenadora adjunta Lilian Amaral, que contamina qualquer um com seu entusiasmo. A idéia surgiu da observação das dificuldades de recepção pelos Arte Educadores da Arte produzida hoje. Para os que foram educados nos princípios do alto modernismo, dentre eles a defesa da especificidade das linguagens artísticas, torna-se difícil a decodificação e a valoração das interconexões de códigos culturais e da imbricação de meios de produção e de territórios artísticos que caracterizam a Arte hoje. A colaboração entre as Artes e os meios de produzi-la vem se intensificando. Nós, arte educadores, ficamos perplexos com a riqueza estética das hibridizações de códigos e linguagem operadas pela Arte Contemporânea, pois fomos obrigados a combater a polivalência na Educação Artística decretada pelo governo ditatorial na década de 70. A polivalência consistia em um professor ser obrigado a ensinar Musica, Teatro, Dança, Artes Visuais e Desenho Geométrico, tudo junto da $5^{a}$ série ao Ensino Médio, sendo preparado para tudo isto em apenas dois anos nas Faculdades e Universidades. Combatemos este absurdo epistemológico. Contudo mesmo naquele tempo, já defendíamos a interdisciplinaridade das Artes. Nosso mote era: "Polivalencia não é interdisciplinaridade" ${ }^{1}$ A interdisciplinaridade era desejada, embora fosse ainda uma utopia para nós.

Agora, a Arte Contemporânea trata de interdisciplinarizar, isto é; pessoas com suas competências específicas interagem com outras pessoas de diferentes competências e criam, transcendendo cada um seus próprios limites ou, simplesmente, estabelecem diálogos.

Os professores, na ausência de parâmetros para estes novos fenômenos, obedecem aos valores dos críticos e curadores, entrevistadores de talk shows, jornalistas, etc que, em geral, têm o mercado como valor dominante. A crítica interessada no artista é coisa rara em nossos dias.

Queremos que os educadores de Arte estabeleçam seus próprios parâmetros de avaliação. Foi para eles e para os agentes 
culturais que idealizamos os Encontros "Interritorialidade: fronteiras intermídias, contextos e educação".

Os artistas e agentes culturais hoje se formam, principalmente, nas Universidades. A maioria delas ainda não percebeu que os currículos engessados pelas especialidades já não respondem às interconexões, interpenetrações e sincretismos gerados por valores culturais mais democráticos e pelas novas tecnologias. Do mesmo modo, poucas Universidades se atualizaram no sentido da ampliação do seu repertório, baseado no código europeu e norte americano branco que sempre as dominou para incluir outros códigos culturais na educação de artistas e atores culturais.

Portanto, queremos chamar a atenção para a interculturalidade, a interdisciplinaridade e a integração das Artes e dos meios como modos de produção e significação desafiadores de limites, fronteiras e territórios que reclamam uma visão rearticuladora do mundo e de nós mesmos.

$\mathrm{Na}$ escola, as artes não só devem ter seu espaço específico como disciplinas no currículo, embora ensinadas através da experiência interdisciplinar mas, também, lhes cabe transitar por todo o currículo, enriquecendo a aprendizagem de outros conhecimentos, as disciplinas e as atividades dos estudantes. Estamos falando do que oficialmente se designou transversalidade curricular, um termo que Cesar Coll copiou para nosso PCN do Currículo Nacional da Inglaterra o qual criou as disciplinas e temas "cross-curriculum".

Arte como disciplina transversal, atravessando todo o currículo, se aproxima do que Herbert Read queria dizer em seu livro "Educação através da Arte". Ele falava de Arte como um elemento humano agregador que, interpenetrando outras disciplinas, facilita a aprendizagem pela qualidade cognitiva dos gestos, do som, do movimento e da imagem. Hoje, quase 60 anos depois de Read, James S.Catteral em seu livro Critical Links: Learning in the Arts and Student Social and Academic Development demonstra a Arte como estimuladora do conhecimento de outras disciplinas como a História, a Matemática, o Português, o Inglês, etc.

Catteral estudou mais de 100 pesquisas que determinaram como a Arte interfere positivamente no desenvolvimento da cognição para outras áreas de conhecimento. Há maior número 
de pesquisas demonstrando como a musica desenvolve a performance acadêmica das crianças; seguem-se, também, numerosas pesquisas sobre a teatro e menor número de pesquisas têm sido feitas para demonstrar os efeitos das Artes Visuais e da Dança no desenvolvimento da capacidade de aprender outras áreas do saber. Sob o efeito das Artes, as áreas mais afetadas positivamente ou expandidas são: ler e escrever; linguagem oral; apurar foco de atenção e inteligência espacial. Cerca de 3000 estudos em Cognição e Inteligência Artificial comprovam que a inteligência espacial tem enorme impacto na vida humana e na aprendizagem. As palavras que ouvimos e lemos são relacionadas com significados através do raciocínio espacial, nos explica Catteral. Nas pesquisas que examinou, encontrou 84 efeitos positivos das Artes, entre eles, a habilidade de resolver conflitos, facilidade de expressão, persistência, imaginação, criatividade, espírito de colaboração, cortesia, tolerância, etc. Mas as últimas são qualidades sociais, o grande número de pesquisas que Catteral examinou comprovam mesmo é que Arte desenvolve a inteligência. Portanto, não basta ensinar Arte com horário marcado, mas é recomendável introduzi-la transversalmente em todo o currículo. O raciocínio inverso também é verdadeiro.

As novas midias estão produzindo muitos materiais bons para estimular a interdisciplinaridade e a tranversalidade da Arte nas salas de aula.

A TV Cultura editou uma série de excelentes programas que podem ser adquiridos em vídeo ou em DVD acerca da Matemática e das Artes. Produzidos por Walter Silveira, tiveram com consultor um matemático afeito às Artes, o Prof. Barco da Escola de Comunicações e Artes da Universidade de São Paulo, e são magníficas sugestões de como levar a Arte a esclarecer complicadas noções matemáticas.

A aprendizagem da História através das imagens da Arte já vem sendo explorada por historiadores/professores da USP e algumas teses e dissertações já foram produzidas nesta linha, da qual a Prof. Dra. Teresa Aline Pereira de Queiroz é uma brilhante adepta. Na série de livros didáticos de História do Brasil produzida por Carlos Guilherme Motta (et alli) há uma tentativa de ilustrar em profusão com obras de Arte o texto embora 
não tenha havido a necessária articulação com professores de Arte e, por isso, se perdeu a possibilidade de, através da leitura das imagens da Arte, se chegar a deduzir fatos, situações e contextos históricos, muitas vezes revelando visões ou interpretações conflitantes de um mesmo fato.

Uma boa aula sobre História das Bandeiras poderia partir da análise do monumento às bandeiras de Victor Brecheret, comparando-o com a sua releitura crítica feita por Regina Silveira. As distorções operadas pela artista na sombra do monumento são um alerta para se fazer uma história crítica ou uma crítica da História que endeusa os bandeirantes em nome da hegemonia branca sem ser capaz de perceber o alcance da desumanização, da matança por eles operada na população indígena da época. Conquistaram território dizimando seus habitantes.

No caso das aulas de língua estrangeira, a tese de Ana Amalia Barbosa (ECA, USP, 2002) comprova que é mais fácil aprender inglês através da Arte, analisando ou lendo obras de Arte que denotam esteticamente a vida e o cotidiano da Inglaterra ou dos Estados Unidos ou da Austrália. Conhecer a cultura do país ajuda a memorizar sua língua. Língua é cultura.

Passei, depois de ler a referida tese, a me perguntar porque as Universidades não preparam professores de competências mistas. Já que Inglês tem poucas horas de aula por semana e Arte também, se poderia preparar um professor para dar ambas as disciplinas. O que não se justifica é o que está acontecendo: entregar as aulas de Arte para um professor de Inglês que não estudou Arte ou vice versa ,só para complementar horário, isto é, salário. Devíamos deixar de ser hipócritas e começar a encarar a realidade criando cursos para dupla preparação e analisar os resultados. Se der errado, se as crianças não aprenderem nada, muda-se de sistemática antes que elas saiam da escola. Experimenta-se muito pouco na educação no Brasil. Cada solução aparece sempre como a definitiva, a última palavra, o remédio certo para nossas incertezas. Com isto, perdemos muito tempo agarrados a propostas que não dão certo, como é o caso dos PCNs. Eles vão fazer dez anos no próximo ano e nunca suas conseqüências e ações foram avaliadas pelo governo que os editou ou pelo atual poder do MEC. Se pensa em modifica-los sem dados 
acerca de sua aplicabilidade nos oito anos de implementação. As incertezas são estimulantes desde que se experimente e avalie as soluções propostas.

O computador é um instrumento excelente para integrar conhecimento e, por outro lado, há pesquisas mostrando que o domínio da máquina se dá mais divergentemente e eficazmente se é feito através da Arte. O trabalho de Mercedes Frigola, professora da Rede Municipal de São Paulo, em 2004, comprovou isto. Podemos usar seu trabalho como excelente exemplo de interdisciplinaridade e de um ensino de Arte de qualidade. Tomei conhecimento do trabalho de Mercedes durante uma pesquisa encomendada pelo CCBB-SP à empresa La Fabbrica, a qual foi analisada por mim, Rejane Coutinho e Heloísa Margarido Sales.

Farei um relato sucinto do trabalho de Mercedes usando todas as fontes disponíveis pela pesquisa: seus relatos, as observações da agente de campo, referida como Maíra no texto, a comunicação com Stella a orientadora de registros, os trabalhos dos alunos e um questionário respondido por ela.

\section{Relato: professora Mercedes Frigola Pardo}

\section{Objetivos}

Trabalhar as exposições de 2004 do Centro Cultural Banco do Brasil com um $5^{\circ}$ ano do ensino fundamental, utilizando as tecnologias disponíveis no laboratório de informática educativa da escola.

Produzir e experimentar suportes e maneiras diversificadas de registros.

Mercedes foi uma das pioneiras do primeiro e-group de arte-educadores no Brasil, criado por Ana Maria Schultze na internet. No início, era o único e-group de arte-educadores e Mercedes foi assídua correspondente. Hoje, temos vários e-groups de arte-educadores, inclusive o da Federação de Arte Educadores do Brasil. $\mathrm{Na}$ ocasião em que se engajou na pesquisa, Mercedes era professora Orientadora de Informática Educativa de sua escola.

Sobre a exposição Arte da África, os alunos iniciaram o trabalho com desenhos tradicionais, lápis colorido sobre papel, 
onde produziram bem humorados desenhos sobre o filme Kiriku e a feiticeira, e outros desenhos mais infantis, ainda classificáveis como esquemáticos (figuras 176 a 181). Em alguns desses desenhos, nota-se que o aluno busca romper o esquema pela precisão do traço e pela tentativa de representar diversos planos, isto é, a perspectiva através do tamanho dos objetos. No desenho da figura 178, por exemplo, as flores são mero decorativismo e a arvore é desenhada de forma a demonstrar a sua distancia em relação ao espectador. É o que alguns chamam de perspectiva intuitiva. Já a proporção entre criança e adulto é equilibrada, apontando para o início do realismo.

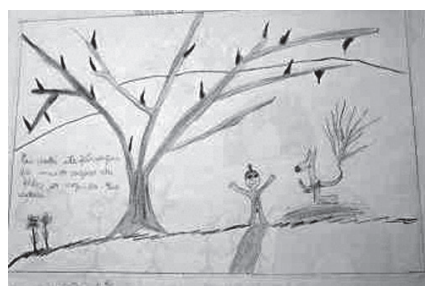

Figura 176

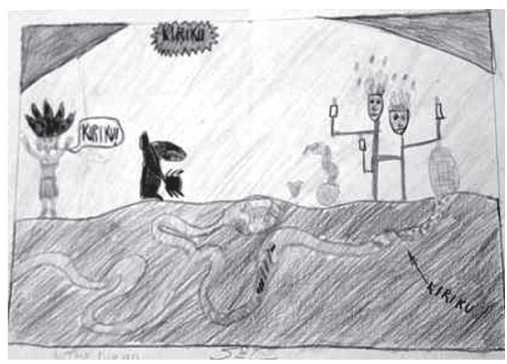

Figura 177

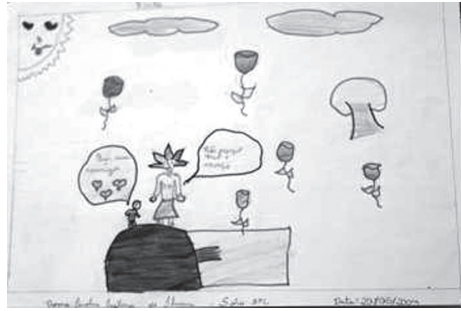

Figura 178

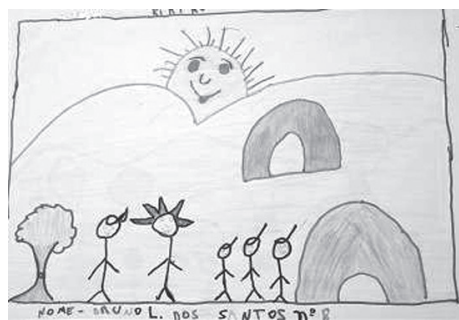

Figura 180

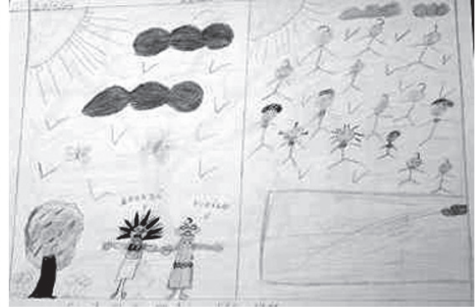

Figura 179

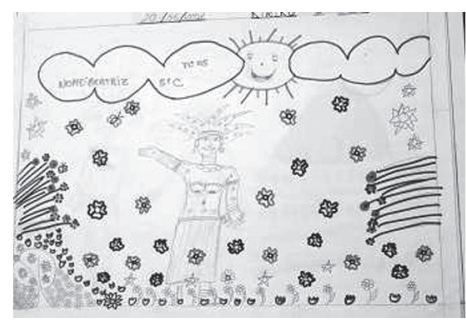

Figura 181 
Mercedes levou os alunos a pesquisar sobre cultura africana em sites, visitando inclusive o site do CCBB. No computador, elaboraram desenhos gráficos a partir dos padrões de design africano. Além de trabalhar interdisciplinarmente, ela multiplicou o uso dos materiais, estimulando outros professores e a coordenação da escola a usá-los. Para ela, a exposição Rosana Palazyan. O lugar do sonho foi a mais fácil de trabalhar "pois a violência atinge a todos". A mais difícil foi a Arte da África "pelo desconhecimento do tema". Vejamos o que relatou:

\section{Exposição Arte na África (abril 2004)}

\section{Objetivos}

- Preparar os alunos para a visita à exposição;

. Diagnosticar os conceitos que os alunos têm sobre cultura, museus, centros culturais e espaços públicos expositivos em geral;

- Dialogar e refletir com a classe sobre a influência da cultura africana na cultura brasileira;

- Por meio de pesquisa orientada, fazer com que os alunos encontrem informações sobre arte africana.

\section{Atividades}

Os alunos foram questionados sobre seu entendimento a respeito de cultura e foram estimulados a apontar exemplos da influência da cultura africana na cultura brasileira. Conversamos sobre a função e importância de espaços públicos expositivos, e como usufruir desses espaços. Em seguida, projetei a imagem do mapa da África na parede e expliquei qual a região contemplada pela exposição. A seguir os alunos fizeram sua pesquisa e também responderam as seguintes questões no site: http://www.edukbr.com.br/artemanhas/arte_africana.asp 1- Para que é criado o objeto de arte na cultura africana?

2- Quais materiais são usados nas esculturas africanas?

3- Que significado têm e para que são usadas as máscaras africanas?

4- Com quais materiais são confeccionadas essas máscaras? 
Alguns alunos ao terminarem a pesquisa navegaram pela exposição virtual no site http://www.bb.com.br/appbb/portal/ hs/africa/index.jsp

Sala de aula (01.04.2004): Foi feita reflexão a respeito das respostas realizadas na aula anterior e sobre a visita à exposição. A professora de arte solicitou que fizessem um desenho de observação de alguma reprodução constante no caderno que receberam na visita e que trabalhassem o fundo da composição com grafismo.

\section{Atividade 2: Construção de Site}

\section{Objetivos}

- Registrar as impressões e o que foi aprendido e observado na visita à exposição, com foco nas obras vistas.

. Fazer com que os alunos organizem seus pensamentos sobre a presença da cultura africana na cultura brasileira e os registrem.

. Utilizar o meio eletrônico como forma de expressão, criação e comunicação de suas idéias, criando páginas web que comporão o site da classe sobre o tema, usar pesquisa na internet para encontrar imagens e informações.

- Aplicar técnicas de composição visual e teoria das cores para a criação das páginas web.

\section{Desenvolvimento}

1. Laboratório de Informática Educativa (30.04.2004):

Pedimos aos alunos que citassem palavras relacionadas ao que viram na exposição e outras que identificassem a presença da cultura africana na brasileira. Essas palavras foram escritas no quadro branco, para que ficassem visíveis para todos: "máscaras, tambor, esculturas, colares de miçangas e sementes, jóias, deuses, barro, cobre, marfim, reggae, axé, Bahia, acarajé, batuques, danças coletivas, tapioca, capoeira, candomblé, macumba, tartaruga, samba, turbante ("A professora de História usa tur- 
bante, ela disse que veio da África, ela é negra", fala dos alunos"). A seguir, foram orientados a entrar nos sites Google ou Cadê, para procurar por esses termos na busca por imagens e, ao encontrar a imagem desejada, salvá-la na pasta específica da dupla (os alunos trabalham em duplas nos computadores).

\section{Data 14.05.2004:}

Foi explicado novamente aos alunos que iniciariam nessa aula a construção das páginas do site e que as páginas das duplas teriam ligação - links com todas as outras páginas do site da classe. Abriram o programa editor de páginas web (Front Page) e foram instruídos a salvarem as páginas com nomes específicos em suas pastas (África 01, África 02, etc, correspondentes a cada computador/dupla), a seguir tiveram que centralizar o cursor e inserir uma tabela com 2 linhas e 2 colunas. Nessa etapa do processo fiz com que percebessem que o que estavam fazendo era semelhante ao que fazem quando criam composições visuais em suporte material como o papel, na construção de um cartaz, por exemplo, ou seja, que estavam criando uma composição visual. Depois disso tiveram que inserir na tabela uma das imagens de obra da exposição e, na célula ao lado registrar o que sabiam sobre a obra. Para auxiliar os alunos que tinham dificuldade, sugerimos que lessem o caderno recebido na exposição e as anotações feitas por eles. Salvaram as alterações.

\section{Data 28.05.2004:}

Deverão inserir na linha inferior da tabela uma das imagens guardadas que seja representativa da cultura brasileira com influência africana e escrever algum comentário a respeito. A seguir habilitarão os links nas páginas e formatarão as fontes e o plano de fundo, aplicando a teoria das cores.

\section{Avaliação}

A avaliação está sendo feita continuamente, motivando a auto-avaliação dos alunos.

Observações: 
- Durante a listagem das palavras, quando um aluno citou "macumba", outros argumentaram: "Não era macumba! O monitor explicou! Era uma peça ligada à religião, não macumba!”

- O que foi trabalhado na escola em relação aos conceitos não foi suficientemente profundo para a maioria dos alunos, o que mais ficou retido neles foram as informações passadas na exposição.

- O prazo previsto para o desenvolvimento desta atividade não foi cumprido, pois o número de aulas previstas na informática acabou não acontecendo: eu tive que faltar um dia, no outro foi dia de eleição no sindicato dos professores e os alunos não foram à escola, na semana seguinte tive reunião na Coordenadoria de Educação e a professora de Arte não quis se aventurar sozinha no laboratório com a classe.

Respondendo à Stella, diz a professora Mercedes:

Em relação a sua observação quanto à contextualização das obras da exposição, fizemos isso já antes de irmos à exposição. Vários alunos perceberam que no momento da visita é realmente necessário prestar atenção às explicações do monitor, notaram que a falta de atenção de alguns impediu a produção de trabalhos melhor elaborados pelas duplas.

No que diz respeito ao aspecto de mecanismos e espaços de preservação do patrimônio, discutimos com eles e passamos as questões abaixo relacionadas. Segue também a transcrição de algumas respostas dadas por eles:

1- Explique o que você viu de interessante no caminho até o CCBB?

"Quando os policiais estavam revistando pessoas na praça da Sé", "Eu gostei de ver um teatro, não sei exatamente, mas era muito legal, era do lado do metrô Tiradentes", "Policiais, flores, estações de metrô, a Pinacoteca, a Catedral da Sé”.

2- O que você sentiu ao ver o edifício do CCBB? "Emoção e alegria", "Senti que estava dentro de um palácio", "Achei que seria 
legal e bonito e eu acertei!", "Era muito bonito, e eu nunca ia pensar que tinha tudo isso".

3- O que você mais gostou na exposição? "Máscaras, pois eram bem diferentes e também dos tambores", "Da oficina", "Uma escultura que se chama tajaina"

4- Você gostou de participar dessa atividade extra-classe? "Sim, foi muito legal pois nós agora conhecemos um monte de coisas africanas".

As figuras 182 e 183 são exemplos das produções dos alunos na sala de Informática a partir da exposição Arte da África relatadas acima pela professora Mercedes.

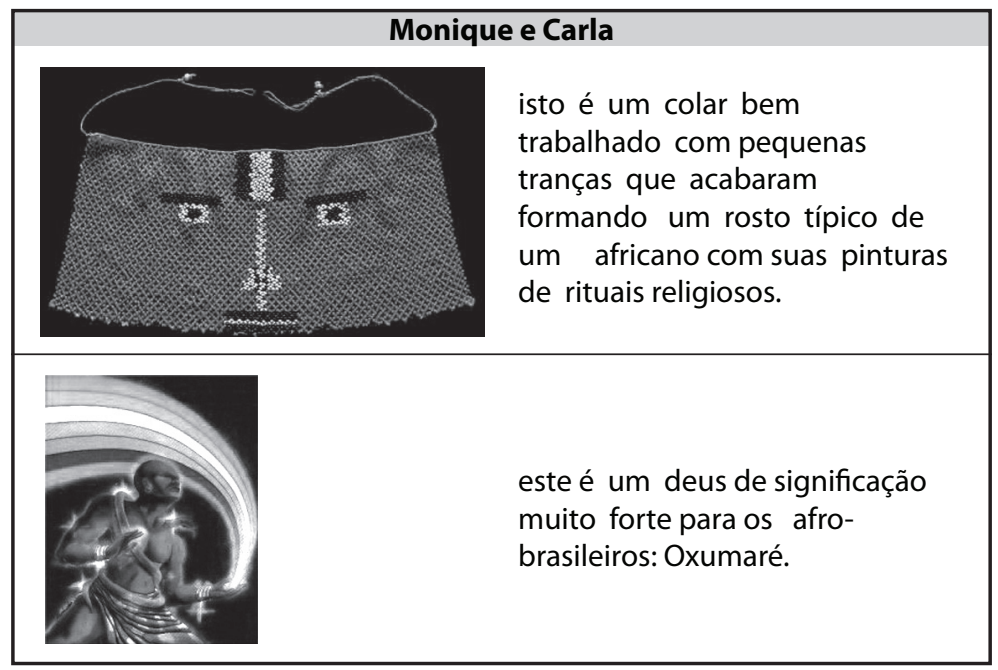

Figura 182 


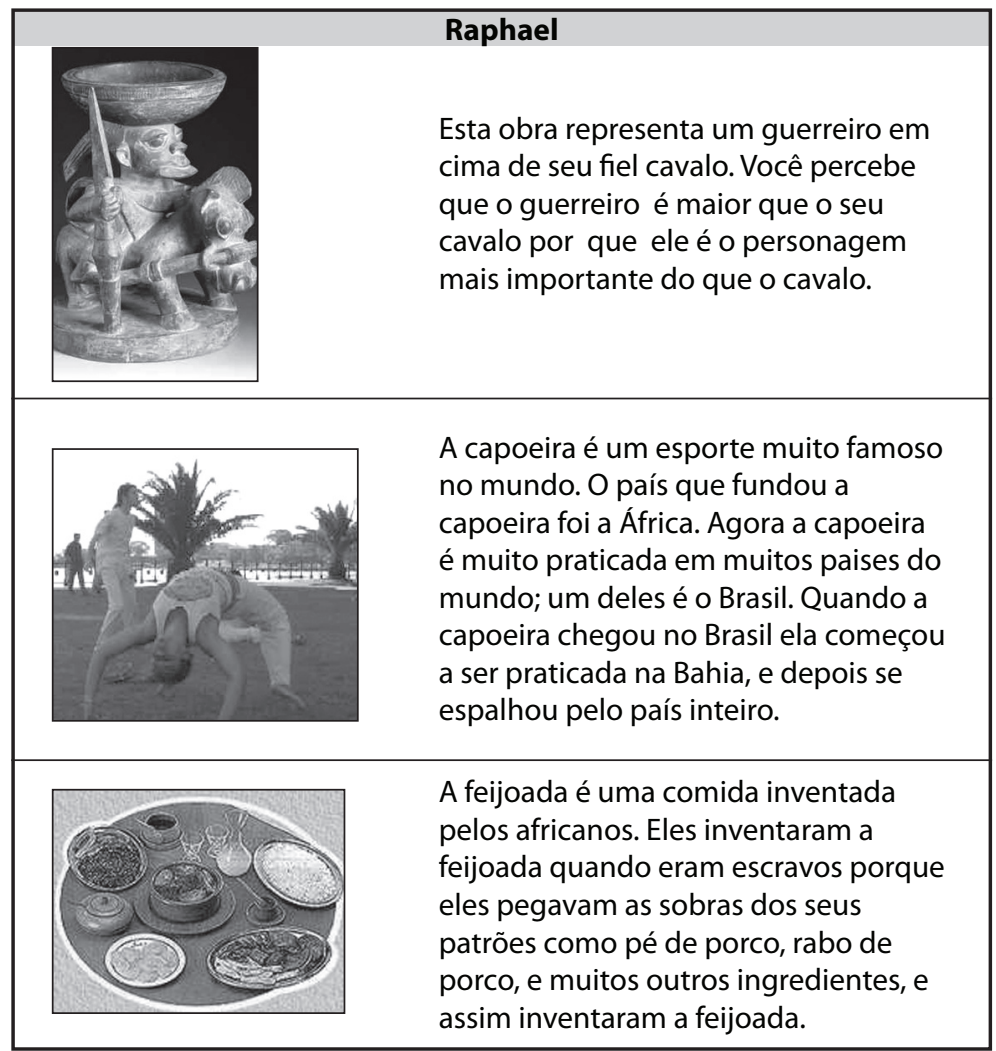

Figura 183

A partir da exposição Nuno Ramos. Morte das casas a professora Mercedes desenvolveu um trabalho em constante progresso e mutação. Em um painel de tecido, colou CDs descartáveis e pediu que os alunos, ao entrar na classe, colocassem os chicletes que estavam mascando nos CDs. Como é proibido mascar chicletes em sala de aula, logo os CDs ficaram cheios. Ela colocou o painel em um lugar que recebesse calor e sol para que observassem a mutação ocorrida pelo derretimento da goma de mascar e os alunos continuaram a acrescentar matéria até a saturação.

Esta foi uma excelente situação para questionamentos da arte contemporânea. Sua exploração de materiais inusitados, in- 
clusive o lixo, seu apego à transformação das obras pela ação do tempo ou fenômenos de diversas ordens como os térmicos, foi observado na obra de Nuno Ramos. Serviu de metáfora também para se pensar a descartabilidade das novas tecnologias e a diversidade da experiência estética.

Vejamos a narrativa entusiasmada e fluente de Mercedes:

\section{Reflexões dos alunos}

$\mathrm{Na}$ época da exposição do artista, não consegui ter contato com a classe. Eles foram à exposição com as professoras Lourdes, de Português, e Luzia, da Sala de Leitura, porque no dia eu tive um encontro de formação na Coordenadoria de Educação. Segundo o relato da Professora Lourdes, eles entenderam bem as explicações dos monitores em relação às instalações.

$\mathrm{Na}$ aula seguinte à visita, conversamos com eles sobre as obras, eles relataram o que tinham visto e em seguida, sentados em duplas abriram arquivos que continham imagens de algumas obras e questionamentos sobre as mesmas, aos quais eles tinham que responder. Conforme iam terminando num arquivo, as duplas trocavam de computadores e respondiam as perguntas dos outros arquivos.

Mostra das reflexões:

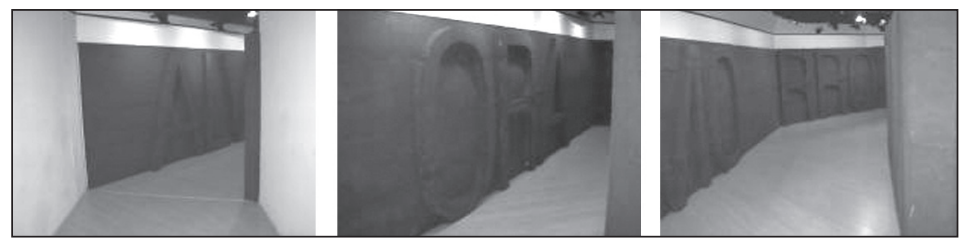

Que tipo de mensagem Nuno Ramos quis transmitir com essa obra?

Que era um labirinto. (Marco)

Logo que nos entramos sentimos um frio na barriga, e nós achamos que ele quis transmitir $P A Z$ 

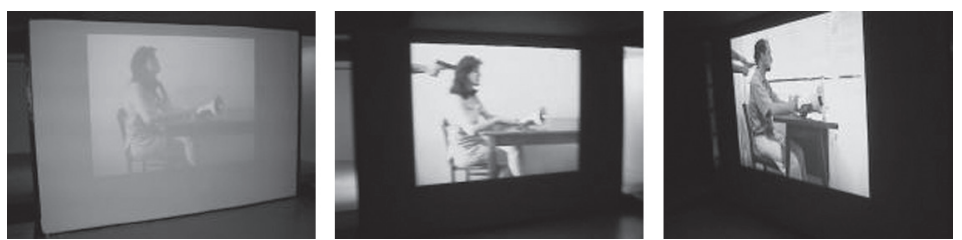

Figura 184

\section{Explique essa obra.}

Esta obra sempre falava alvorada, vinha um cara com uma arma e matava o homem ou a mulher. (alvorada significa o amanhecer do dia). Nicole L. P. e Bruna B. B.

Idem antes das se matarem elas ficavam muito nervosas!!!

\section{Carla e Monique.}

Esta obra é um filme que as pessoas antes de morrer gritavam alvorada.

Camila e Priscilla

\section{Painel de CDs ou Porta-chicletes}

A partir da visita a essa exposição até o final do ano letivo, desenvolvemos uma criação coletiva que envolveu, também, alunos das outras classes. A proposta era grudar chicletes num suporte de T.N.T. com CDs inutilizados. Durante o curso, quando visitamos a exposição de Nuno Ramos, ao ver a obra "Choro Negro", pensei que a classe poderia produzir algo semelhante no sentido de usar materiais que sofressem transformação pela ação do tempo, ambiente e clima. Gostaria de ter extraído as idéias da classe ou feito o painel antes da visita, pois talvez os alunos estabelecessem alguma relação ao ver a obra Choro Negro, mas, como estávamos numa época em que durante várias sextas-feiras seguidas não houve aula por várias razões - eventos na escola, feriados -, resolvi começar a instalação e, pensando em 
materiais disponíveis na escola, resolvi usar CDs sem uso, daqueles que vêm em propagandas (temos um estoque na sala pois há tempos atrás foram usados para decorar a sala), um pedaço de TNT azul e chicletes mascados. Montei um painel colando 16 CDs em 4 fileiras sobre o TNT, formando um quadrado. Combinei com a colega que trabalha comigo na sala de informática que deixaríamos o painel sobre a mesa central e convidaríamos todos os alunos a colarem seus chicletes no painel.

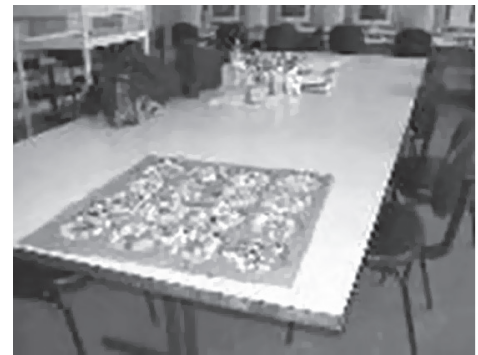

Figura 185

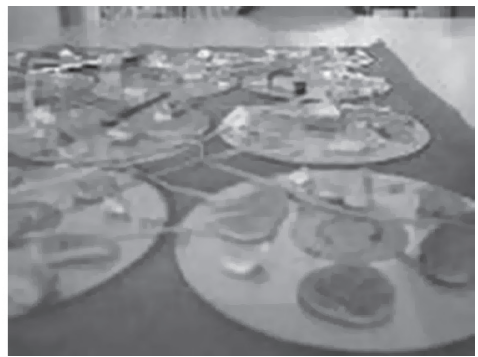

Figura 186

$\mathrm{Na}$ figura 185 vemos o painel sobre a mesa. À esquerda da foto está a porta de entrada. Na figura 186 à esquerda vemos o detalhe do painel.

É regra não mascar chicletes em nenhum local da escola, mas os alunos costumam seguir mais essa regra na sala de informática. Então, sempre que entram na sala, eles sabem que devem jogar os chicletes no lixo. A partir de então, a regra mudou, eles devem colar seus chicletes no painel. Ficaram surpresos pela mudança, alguns se negaram e continuaram jogando os chicletes no lixo, outros acharam divertido, apesar de nojento, outros acharam ridículo.

Após alguns dias, a $5^{\mathrm{a}} \mathrm{C}$ voltou ao laboratório de informática e solicitei que grudasse os chicletes no painel, sem dar-lhes nenhuma explicação. Como as outras classes, tiveram reações variadas e, quando um aluno indagou a razão daquilo, expliquei 
toda a história, ressaltando que seria um dos trabalhos da classe para o projeto. Animaram-se e começaram a "grudação". Expliquei também que posteriormente voltaríamos a conversar sobre essa idéia e sobre arte contemporânea.

Fotos do painel após 2 semanas, tiradas com a WebCam do computador. Já podíamos observar algumas inscrições feitas com caneta sobre os chicletes:
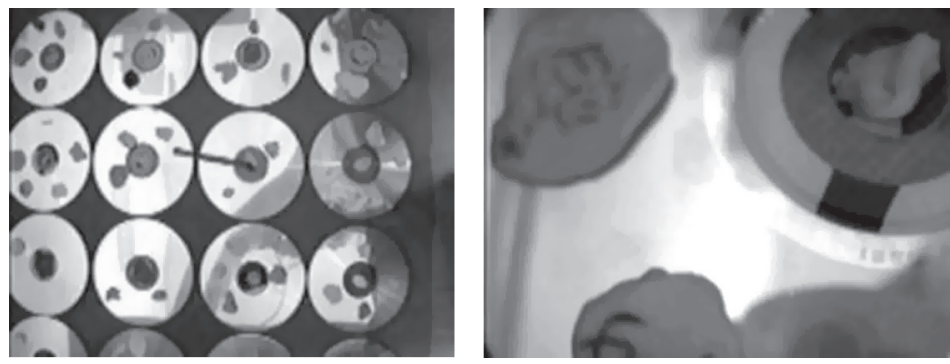

Hoje observei que houve uma mudança na forma como os chicletes estão sendo colados nos CDs. Há alguns chicletes esticados, formando linhas transversais. Há também um pirulito grudado. Fotos do painel tiradas com câmera digital no dia 24.09.2004:

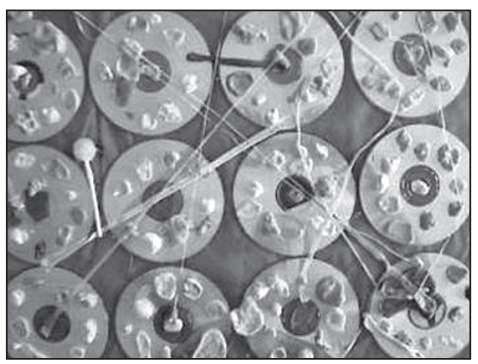


No lado direito da foto vemos um chiclete com bola de ar que murchou, há vários assim. Vemos também inscrições com caneta registrando o nome e série de quem grudou.

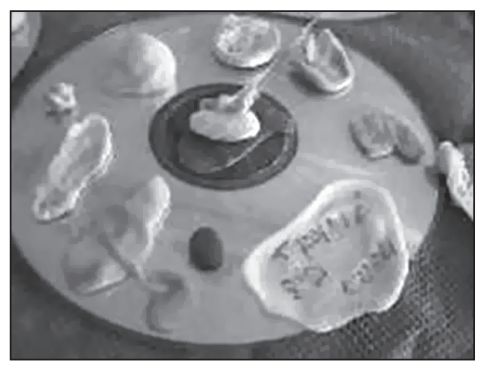

Nessa foto vemos as linhas cruzando o painel e o pirulito.

\section{Blog}

No decorrer do curso criei dois blogs, um para meus registros, pois pensei que assim talvez seria mais prático realizá-los, e talvez esses fossem mais espontâneos, pela própria característica do suporte de registro. Criei outro para a classe, no qual fiz alguns questionamentos aos quais os alunos deveriam responder. Criei também uma enquete na internet, para que a classe votasse no nome que daríamos à obra com CDs e chicletes. Para conhecer os blogs, clicar nos endereços abaixo. Os comentários feitos pelos visitantes dos blogs e alunos podem ser lidos clicando nos links "[Deixe aqui seu recado e veja os comentários deixados por outros visitantes]" e "[(2) Vários Comentários]"

Meus registros: http://eucoma5cnoccbb.zip.net

Blog dos alunos: http://5cnoccbb.zip.net

\section{Registro da aula do dia 25.09:}

Uffaa!!! Mais uma aula! A $5{ }^{\text {a }} \mathrm{C}$, apesar de ser do estilo "da pá virada", tem algumas características interessantes, entre elas o "cavalheirismo" masculino... Talvez um pouco forçado (foram literalmente 'domados' por mim e outros professores a terem 
esse hábito), mas em certos momentos funciona, como na hora em que vão entrar na sala de informática... Quase sempre os meninos param na porta, e somente depois de todas as meninas-damas entrarem é que os gentlemen invadem o laboratório. Registro isso porque ontem observei que um grupo considerável de meninas, quando entraram na sala, foram direto para o painel, com muita pressa, como se tivessem combinado anteriormente, e escreveram sobre os chicletes e o TNT. Uma delas perguntou se podia escrever sobre o TNT, esclareci que podem tudo, só não vale destruir o painel, ou estragá-lo. Não verifiquei como ficou o painel, mas observei que nenhum menino teve essa atitude ontem...

Será que o que elas registraram no painel tem alguma relação com os meninos? Será algo ligado a algum fato ocorrido na classe? Ou perceberam que está sobrando pouco espaço para deixar suas marcas e quiseram garantir logo seu território, antes que outras classes ocupem o terreno? Vou perguntar quando encontrar com elas... Ou será que não pergunto?! Tirei fotos desse momento, mas apenas desse, porque depois foi impossível, não parei 1 minuto.

Pouco depois a Maira chegou e se enturmou rapidinho, conversando com eles, vendo os trabalhos e tirando fotos (eles adoram 1 minuto de fama!), enquanto eu resolvia um probleminha numa parte da rede dos computadores, que não abria os trabalhos-fotos desse dia:

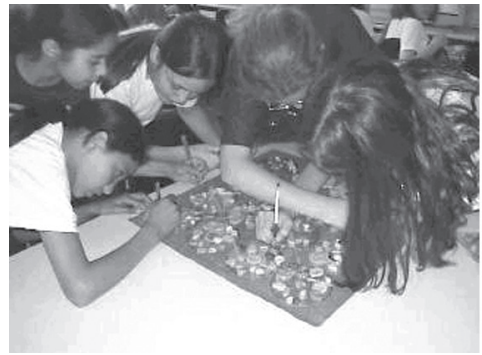

Figura 192

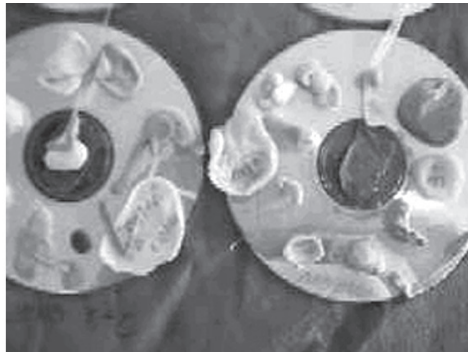

Figura 193 


\section{Registro do dia 09.10.2004:}

$\mathrm{Na}$ semana passada a professora Kelley, que trabalha comigo na informática comentou que talvez o painel não estivesse dando muito certo, porque a professora Nanci, que leva a $5^{\text {a }} \mathrm{C}$ do laboratório para sua aula de Matemática, observou que a classe, antes de descer, quando ela pede a eles que joguem os chicletes no lixo, fazem o contrário, colocam mais chicletes na boca e justificam-se, dizendo que eles têm que grudar no painel da sala de informática. Esclareci as professoras que a proposta é justamente essa, elas entenderam.

Uma de minhas intenções em usar esses materiais - chicletes e CDs - era justamente de estimular a reflexão sobre o consumo excessivo de chicletes por eles, talvez esteja surtindo efeito contrário, mas o fato é que parece que a classe está muito mais envolvida nessa atividade agora, do que quando começamos, o que considero um fato positivo. Falta agora - e falta mesmo, inclusive tempo para isso - refletirmos, discutirmos, lermos a instalação com eles, e construirmos juntos um significado ou múltiplos significados para ela. Embora é claro, a instalação já tenha significado, principalmente para os que estão atuando como autores (grudando chicletes, escrevendo seus nomes, dando opiniões), mesmo que seja um significado muito subjetivo. Quero compilar os 'múltiplos significados' e registrar.

Os chicletes endureceram, algumas tiras transversais ressecaram, a bola do pirulito caiu e há mais inscrições sobre o TNT e os CDs; quando nos aproximamos do painel, podemos sentir o cheirinho dos chicletes, é um cheiro agradável. O painel é 'nojento', mas tem cheiro agradável. Outra contradição ou antagonismo.

A exposição de Nuno Ramos também rendeu uma excelente conversa sobre o Choro Negro e a liberdade intelectual e plástica de Nuno Ramos lidar com os materiais. Mercedes propôs: 


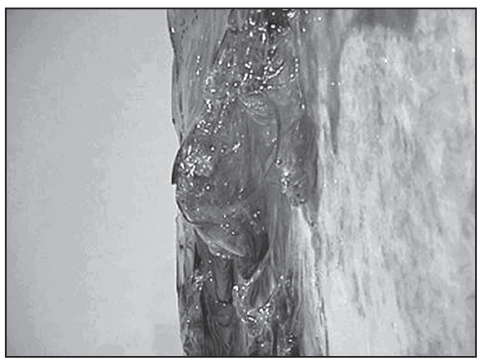

\section{No espaço abaixo, descreva essa imagem}

"É um breu que quando você derreter fica duro. Quando você for fazer a escultura terá que esquentar o breu terá que por formas em volta do breu". Rafael e Verônica.

"É um breu derretido, e tem uns fios atrás do mármore". (anônimo) "A escultura se trata de breu colocado no mármore e quando derretido fica duro". Bruna e Nicole.

"Essa obra tem a forma de sangue". Tábata

"Eu não fui mas acho muito parecido com açúcar derretido". Francielle

"É uma seiva extraída de um tipo de pinheiro chamado breu e colocado em cima de uma pedra de mármore". Isabela e Talita

"É um breu que quando derrete fica duro. Quando você for fazer uma escultura tem que esquentar"

"É um breu duro escorrido num pedaço do mármore". Monique e Carla

"O material apresentado na foto é o Breu". João e Luan

"Essa obra está em cima de uma pedra de mármore, essa obra foi extraída de uma seiva de uma espécie de um pinheiro. O Nuno Ramos ligava essa obra na tomada então ficava quente e começava a derreter". Gabriele e Tamires

"Isto que esta escorrendo na figura é breu derretido em um pedaço de mármore". Guilherme

"Eles estalaram um negócio que esquentava e fazia o BREU derreter”. João e Luan

O trabalho de Mercedes com os alunos e sua capacidade de planejar, falar e escrever sobre, foi elogiado por vários colegas. A apreciação de uns pelos outros foi um fator que demonstra a maturidade e o real interesses dos professores deste grupo por sua área de trabalho. A capacidade crítica como reconhecimento 
de qualidade é mais difícil de se manifestar entre pares que a capacidade para críticas negativas.

Depois que Mercedes criou o blog com os alunos, trabalhos e conversas sobre as exposições eram compartilhados entre eles e outros usuários da Internet. Fizeram animações e alimentaram o blog freqüentemente. $\mathrm{Na} 7^{\text {a }}$ e última visita da agente de campo, Mercedes demonstrou contentamento porque os alunos "não sentiram o trabalho de informática como ligado a nenhuma disciplina específica." Isto nos deixa supor que a professora pretende, com a informática na escola, romper a compartimentação dos saberes, no que se mostra muito atualizada.

Sobre a exposição "Rosana Palazyan". O lugar do sonho que parece ter movido mais seus alunos, Mercedes diz:

\section{Exposição Rosana Palazyan. 0 lugar do sonho}

Antes da exposição 'O lugar do sonho', de Rosana Palazyan, mostrei pelo projetor algumas obras da artista. Os alunos observaram, analisaram, questionaram. Acharam interessante a artista usar suportes não convencionais, como cuecas, fronhas e roupas de bebês. Decidimos trabalhar com os alunos as violências sutis do cotidiano. Conversamos a respeito do relacionamento deles com outras pessoas e, principalmente na escola. Refletimos sobre quais atitudes podem ser adotadas a cada dia para melhorar o convívio, e a proposta foi mostrar isso numa seqüência de 3 ou 4 desenhos. Utilizamos o programa Paint. Terminados os desenhos, montamos uma animação, no sentido da seqüência dos fatos, não do movimento. Para ver maiores detalhes sobre o desenvolvimento do trabalho, ler os registros dos dias $22,24,25$, 27.09 e 08.10 no blog que criei para experimentar mais uma maneira de registrar meu trabalho: http://eucoma5cnoccbb.zip.net 


\section{Exemplo:}

Nome da dupla: Bruna Brito e Íris Gabriela M.

Nome da obra: Solidariedade

Relato: Bem, eu (Íris) tive a idéia de fazer um desenho de solidariedade, como a professora deu duas escolhas: poderia ser uma ação boa ,ou uma ação ruim. Então nos duas tivemos a idéia de fazer uma ação boa, porque achamos que seria mais fácil e passaria uma mensagem melhor. A partir dai escolhemos fazer o desenho de um menino com a perna quebrada que ao derrubar os livros é ajudado por um amigo.
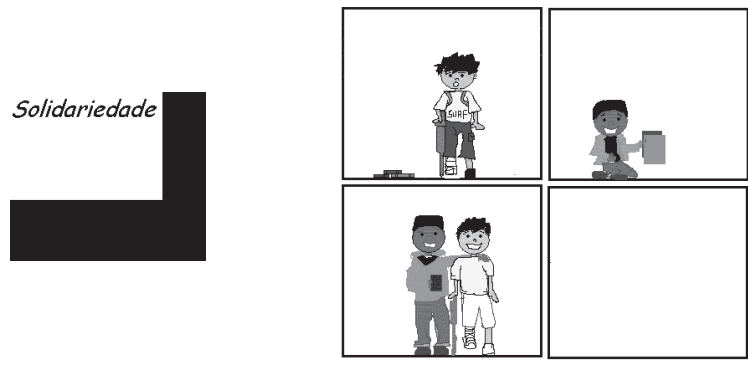

Foi também entregue aos alunos o material educativo da exposição, um folder que continha em cada divisão uma pergunta ou frase que propunham ao aluno expressar-se. A autoria de alguns trabalhos foi omitida para preservar a identidade dos autores.

\section{...um pedido para uma estrela cadente...}
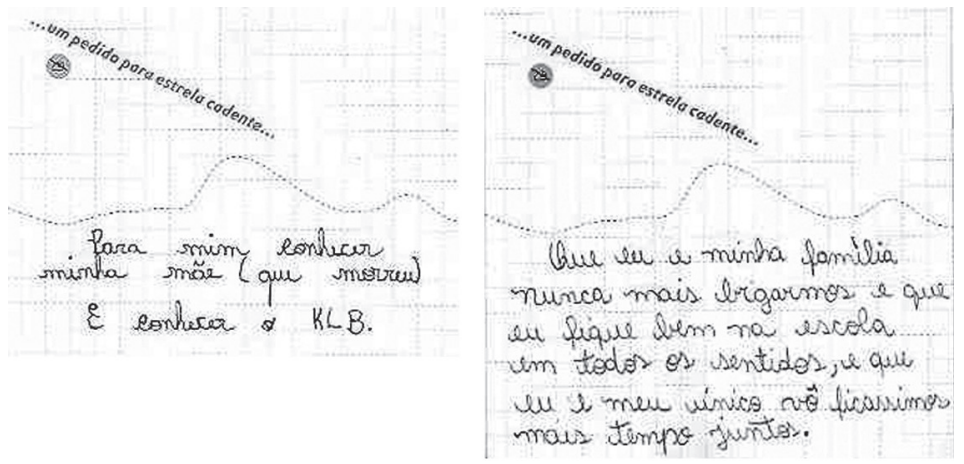


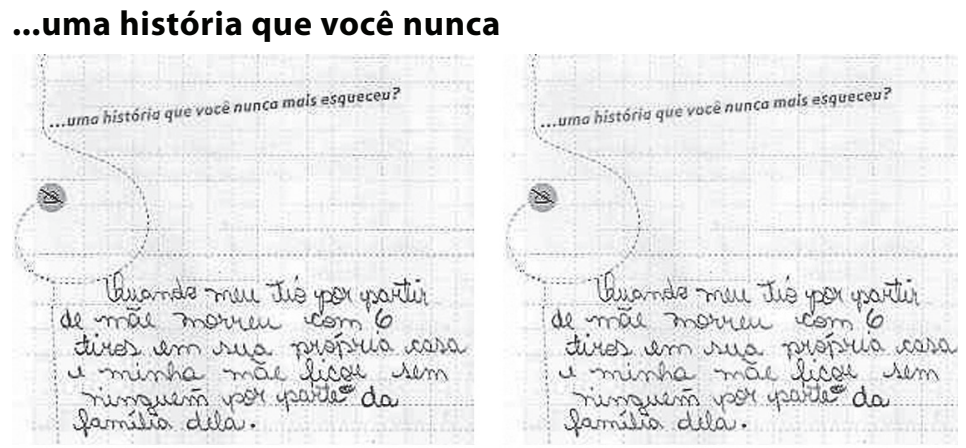

...uma história que você nunca mais esqueceu?
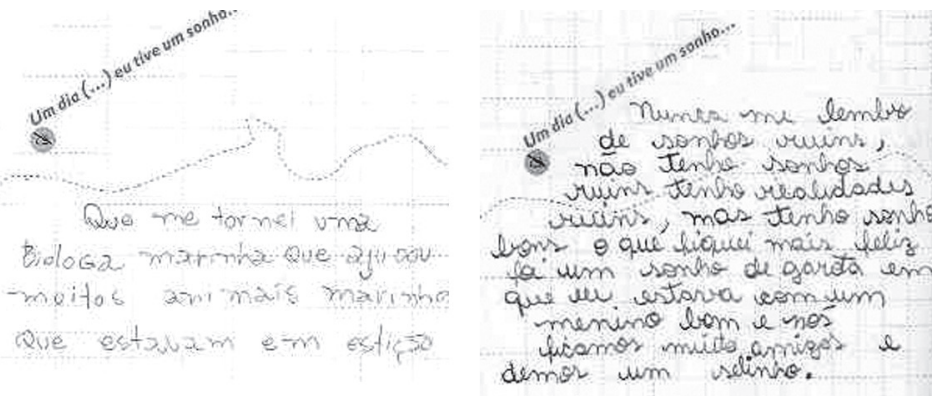

Um dia (...) eu tive um sonho...

Nam Cavla Christina lopers Sfore Parto. Sp $24 / 10 / 92=$ torpital om

- guevoce quer ser quando erescer?

8) $A L E m, D \in G R A N D E$ UMA Ót $M M A$ i ARQUiTE TA U mó e oque quero her mo - que

Vou SERddd

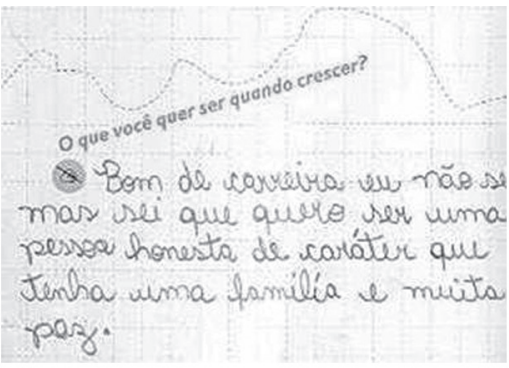




\section{O que você quer ser quando crescer?}
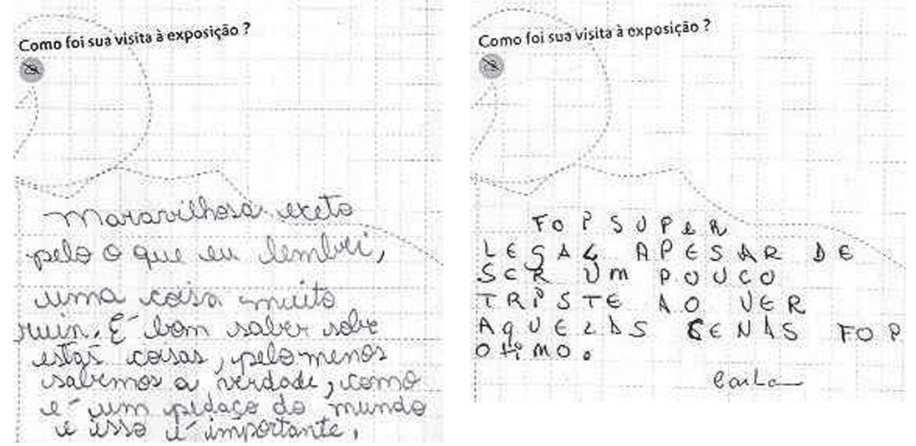

\section{Como foi sua visita à exposição?}
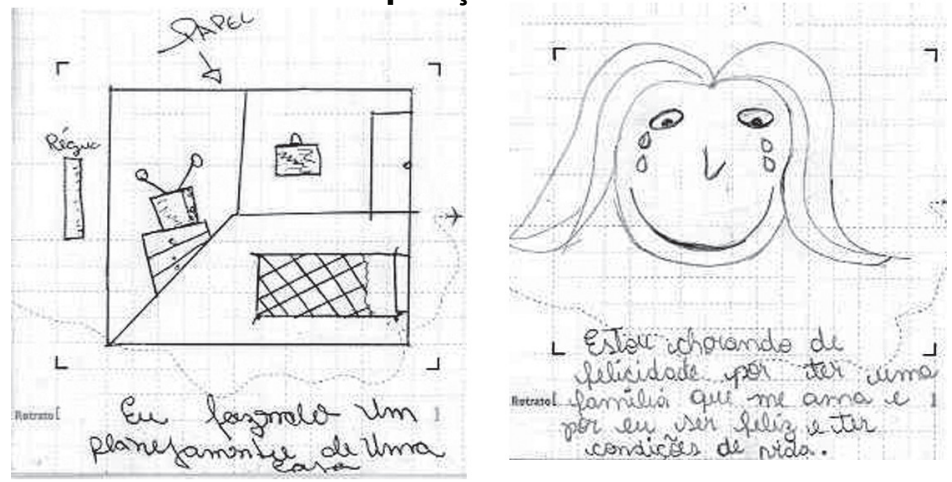

$L$ Estou chorondo de elicidods as ter nimo notrat formilia que me ama e 1 por es user fellizeter. condisies de nido. 


\section{Retrato Exposição Antoni Tàpies}

Não houve tempo para prepará-los para essa exposição. Os registros do que foi possível realizar estão no blog da classe: http://5cnoccbb.zip.net/

As discussões sobre arte, não só acerca da exposição de Tàpies, foram muito ricas. Os alunos aprenderam a falar sobre arte de uma maneira desenvolta. Vejamos o que fala Mercedes:

Registro de aula do dia 05.11.2004:

Iniciamos a aula conversando sobre o painel de CDs. Perguntei o que deveríamos fazer com ele, já que está terminando o ano letivo e quase não há mais espaço para colar chicletes. As respostas foram:

- colocar no sol para ver o que acontece;

- colocar na água para ver o que acontece;

-depois de colocá-lo no sol, deixá-lo em exposição na sala de informática, no biombo.

Seguimos conversando sobre arte contemporânea. Mostrei pelo projetor algumas partes do Hot Site "Isto é Arte?" do Itaú Cultural (clicando em "Isto é Arte?") e fomos conversando sobre o que era apresentado:

- Arte é isto? - porco empalhado - intenção do artista; na obra de Duchamp. Perguntei se lembravam de algo ou algum objeto usado com outra função. Lembraram das obras de Nuno Ramos. - O que a gente acha que é Arte? - disseram que eles também pensavam que arte eram apenas quadros e esculturas, mas que a opinião deles mudou.

- Isto é belo? - conversamos sobre o conceito de beleza, foram quase unânimes em concordar que o que é bonito para uns não é para outros. Perguntei se a obra "Caixa de baratas" mostrada no site lembrava-os de algo conhecido... Alguns poucos responderam... "- O nosso painel de CDs..." e deram risada. foi então que o restante dos alunos concordou, e toda a classe deu risada. 
- Pode mexer numa obra de Arte? - alguns contaram que não sabiam que algumas obras de Arte podem ser tocadas, e que aprenderam durante as exposições. Um deles citou que numa das obras da Rosana Palazyan, isso foi possível, como na que havia muitos balões.

- A arte precisa de público? - concordaram, pois assim as pessoas pensam no que o artista propôs ao criar a obra.

Em seguida mostrei o site e o blog para a classe, contei que para podermos colocar as fotos deles na internet, a escola precisa da autorização dos pais por escrito, que eu havia entregue há alguns dias. Expliquei então o que é um blog e como funciona, para minha surpresa apenas 1 aluna sabia usar blogs. Demonstrei pelo projetor que eu havia colocado alguns questionamentos e que eles deveriam fazer comentários a respeito. Antes de entrar no blog, alguns alunos questionaram que não tinham terminado de consertar as animações, daí expliquei que nas próximas semanas resolveríamos esse problema, mesmo que fosse emprestando a aula de algum outro professor, ou usando minhas horas-atividade. Iniciaram então a interação no blog. Parecia que estavam curtindo bastante essa etapa... Dois alunos acessaram o blog de suas casas e colocaram alguns comentários. Alguns dias depois dessa data criei uma enquete na internet para que a classe e quem mais desejar vote na eleição do nome do painel de CDs. Foi colocado um link para a enquête no blog da classe e também no site da escola.

No final do ano levei o painel para casa e, numa tarde ensolarada e quente pendurei o painel no varal, sob o sol forte. Ficou ali algumas horas, e observei que os chicletes ficaram moles e derreteram. Atualmente (março de 2005) o painel está guardado em minha casa. Os alunos da $5 \mathrm{C}$ de 2004 já me perguntaram sobre a obra e pediram que eu a leve de volta para a escola, vou fazer isso nos próximos dias e a deixarei no biombo da sala de informática, como combinado anteriormente. Pretendo usar a obra-instalação como material para leitura e fruição em minhas aulas, já que este ano, retornei às minhas aulas de Arte. Penso que será interessante todos os alunos 'relerem' o que criaram. Pretendo também que todas as classes que forem 
ao laboratório votem para elegermos o nome da obra, afinal, foi uma criação coletiva.

mefrigola@yahoo.com.br

Blog: http://eucoma5cnoccbb.zip.net

Mercedes foi muito cuidadosa em dar crédito a outras pessoas da escola que trabalharam com ela:

\section{Créditos}

Participação no curso Diálogos e Reflexões, Ver e Perceber a Arte: Coordenação e desenvolvimento das atividades do projeto na escola: professora orientadora de Informática Educativa Maria das Mercedes Frigola Pardo.

Colaboração: Funcionários da EMEF Prof. Máximo de Moura Santos, especialmente a professora Maria de Lourdes Rebelo Roque - Português.

Participação e autoria dos trabalhos: Alunos da $5^{\text {a }}$ série $\mathrm{C}$ de 2004, da EMEF Prof Máximo de Moura Santos, São Paulo/SP.

Orientação: equipe arteducação produções, equipe La Fabbrica do Brasil, Centro Cultural Banco do Brasil.

Maíra - agente de campo da pesquisa.

Stella - orientadora dos registros dos professores que participaram da pesquisa.

Fotos: A maioria das fotos é de minha autoria, tiradas durante as aulas e nas exposições, quando era permitido. Outras foram copiadas dos HotSites do CCBB. A foto da obra Choro Negro foi cedida pelo professor Rebelo.

Sua bibliografia é de sites e links:

Site "quintacnoccbb"

http://geocities.yahoo.com.br/quintacnoccbb

Blog da classe para o trabalho

http://5cnoccbb.zip.net 
Blog com meus registros do trabalho

http://eucoma5cnnoccbb.zip.net

Centro Cultural Banco do Brasil

Arte da África

http://www.bb.com.br/appbb/portal/hs/africa/vst/

HistoriaArte.jsp

\section{Nuno Ramos}

http://www.fortesvilaca.com.br/artistas/nuno_ramos/

http://www.sampa.art.br/saopaulo/biog\%20Nuno\%20Ramos.htm

Enciclopédia de Artes Visuais do Itaú Cultural-biografia

ArtigoCompl.jsp-Artigo.codigo $=841(\mathrm{CCBB})$

\section{Rosana Palazyan}

http://www.artnet.com/artist/13015/Rosana_Palazyan.html

\section{Antoni Tàpies}

http://www.fundaciotapies.org/

http://www.bb.com.br/appbb/portal/hs/anv/tap/index.jsp

http://www.mac.usp.br/exposicoes/99/secarte/obras/

tapies.html

http://www.hoy.com.ec/especial/ibero/antoni.htm

http://www.revistamuseu.com.br/galeria.asp?id=5489

http://www.el-mundo.es/larevista/num135/textos/tapi.html

\section{Site da EMEF Prof. Máximo de Moura Santos}

www.maximo.cjb.net

Mercedes tirou proveito de todo o material fornecido pelo $\mathrm{CCBB}$, isto é, textos e transparências, assim como o material distribuindo pelo educativo aos alunos os quais elogia muito. Trata-se de uma professora que embora privilegie o computador como instrumento, não despreza os outros meios mais tradicionais e promove um verdadeiro desenvolvimento do pensar nos seus alunos. Além de leva-los a experiências com diferentes meios os está ensinando a dominar o computador de modo inventivo. 
Estimula a interdisciplinaridade em sua escola e a realiza associando a aprendizagem do domínio do computador à Arte.

Arte resulta de um processo integrador da mente. A chamada "ordem oculta" da Arte nos torna mais inteligentes.

\section{Nota}

1- BARBOSA, Ana Mae. Arte-Educação: conflitos/acertos. São Paulo: Max Limonad, 1984, p. 68-115. 


\section{Ana Mae Barbosa}

Ana Mae é professora aposentada, atuante na pós-graduação em arte-educação da ECA-USP (SP). Autora de 16 livros sobre Arte e Arte/Educação e 125 artigos traduzidos para vários idiomas (inglês, francês, espanhol, sueco, polonês, japonês etc.). Foi diretora do Museu de Arte Contemporânea de São Paulo de 1986 a 1993.

\section{Mercedes Frigola Pardo}

Professora de Arte na rede municipal de São Paulo, atuando desde 1997 como professora orientadora de informática educativa na EMEF Prof. Máximo de Moura Santos na zona norte da cidade, onde criou e desenvolveu, entre outros, o PROJETO INTERM@XI, antigo PROJETO HTML remodelado. 